Controlled release ibuprofen-poloxamer gel for epidural use - A pharmacokinetic study using microdialysis in pigs

\title{
Paavola, Anne
}

2016-11

Paavola , A , Bernards , C M \& Rosenberg , P H 2016 , ' Controlled release ibuprofen-poloxamer gel for epidural use - A pharmacokinetic study using microdialysis in pigs ' , European Journal of Pharmaceutics and Biopharmaceutics , vol. 108 , pp. 180-186 . https://doi.org/10.1016/j.

http://hdl.handle.net/10138/229644

https://doi.org/10.1016/j.ejpb.2016.09.006

publishedVersion

Downloaded from Helda, University of Helsinki institutional repository.

This is an electronic reprint of the original article.

This reprint may differ from the original in pagination and typographic detail.

Please cite the original version. 
Research paper

\title{
Controlled release ibuprofen-poloxamer gel for epidural use - A pharmacokinetic study using microdialysis in pigs
}

\author{
Anne Paavola ${ }^{\mathrm{a}, \mathrm{b}, *}$, Christopher M. Bernards ${ }^{\mathrm{b}, 1}$, Per H. Rosenberg ${ }^{\mathrm{c}}$

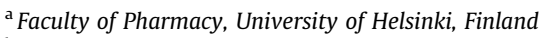 \\ ${ }^{\mathrm{b}}$ Department of Anesthesiology, University of Washington, Seattle, USA \\ ${ }^{\mathrm{c}}$ Department of Anesthesiology, Helsinki University Central Hospital, Finland
}

\section{A R T I C L E I N F O}

\section{Article history:}

Received 23 June 2016

Revised 3 September 2016

Accepted in revised form 6 September 2016

Available online 09 September 2016

\section{Keywords:}

Controlled release

Epidural

Intrathecal

Ibuprofen $\mathrm{Na}$

Injectable

Microdialysis

Poloxamer 407 gel

\begin{abstract}
A B S T R A C T
In order to avoid the risks of sideeffects of epidural local anesthetics and opioids, the use of nonsteroidal anti-inflammatory drugs (NSAIDs) epidurally would be an interesting option of analgesic therapy. The fairly short duration of action of spinally administered NSAIDs, e.g., ibuprofen, may be prolonged by using controlled release poloxamer gel formulation. Using a microdialysis technique we studied the epidural and intrathecal pharmacokinetics of ibuprofen after its epidural administration as a poloxamer 407 formulation or a solution formulation. In addition, plasma ibuprofen concentrations were analyzed from central venous blood samples. Ibuprofen concentrations in the epidural space were significantly higher and longer lasting after the epidural gel injection compared with the epidural solution injection. The epidural AUC of ibuprofen was over threefold greater after epidural ibuprofen gel injection compared with the ibuprofen solution injection $(\mathrm{p}<0.001)$. The systemic absorption of ibuprofen from $25 \%$ poloxamer 407 gel was very low. The in situ forming poloxamer gel acted as a reservoir allowing targeted ibuprofen release at the epidural injection site and restricted ibuprofen molecules to a smaller spinal area. Ibuprofen diffusion from the epidural space to the intrathecal space was steady and prolonged. These results demonstrate that the use of epidurally injectable poloxamer gel can increase and prolong ibuprofen delivery from epidural space to the CSF enhancing thus ibuprofen entry into the central neuroaxis for spinal analgesia. Further toxicological and dose-finding studies are justified.
\end{abstract}

(c) 2016 Elsevier B.V. All rights reserved.

\section{Introduction}

Different systems to control epidural drug release have been studied during the last years, including the use of lipid solutions [1], cyclodextrin [2], liposomes [3], microparticles [4,5] and emulsified solutions [6]. The results have been to some extent conflicting [7], and only bupivacaine liposomes have been studied epidurally in humans $[8,9]$. So far, to our knowledge, for general clinical epidural use there is only one slow-release liposome product of morphine available on market (DepoDur $\left.{ }^{\circledR}\right)$ [10]. One bupivacaine liposome formulation is on market for regional pain treatment $\left(\right.$ Exparel $\left.^{\circledR}\right)$, but it is not indicated for epidural or intrathecal use [11].

Intravenously administered non-steroidal anti-inflammatory drugs (NSAIDs) can penetrate into the CSF $[12,13]$ and some have been administered intrathecally in pain patients [14]. The possibil-

\footnotetext{
* Corresponding author at: Faculty of Pharmacy, Biocenter 2, P.O. Box 56, 00014 University of Helsinki, Helsinki, Finland.

E-mail address: anne.paavola@helsinki.fi (A. Paavola).

1 C.M.B. deceased.
}

ity of using indomethacine instead of corticosteroids epidurally has been explored in patients with postlaminectomy syndrome [15]. The spinal analgesic and anti-inflammatory effects of nonsteroidal anti-inflammatory drugs (NSAIDs) seem to be related to their ability to inhibit cyclo-oxygenase enzyme and the synthesis of prostaglandins [16,17], thus blocking the excessive sensitivity to pain induced by the activation of the spinal glutamate and substance $P$ receptors $[18,19]$. Since NSAIDs act through an enzymatic system instead of receptors the risks of spinal opioids, such as tolerance, respiratory depression, urinary problems, motor blockade and dependence [20] are unlikely to develop in epidural use of NSAIDs. Ibuprofen is known as a potent oral NSAID, but has been found to be able to act also on the spinal cord reducing pain even more efficiently after intrathecal administration than after systemic administration [18]. Ibuprofen can produce significant analgesia after epidural administration [21], but the biological half-life of ibuprofen is fairly short ( $\mathrm{t} 1 / 2 \sim 2 \mathrm{~h})$.

In epidural analgesia and anesthesia it would be important that the application of drug molecules is localized near the epidural injection site and spot-targeted drug delivery through the spinal 
membranes into the cerebrospinal fluid (CSF) could be achieved. Poloxamer is a biocompatible polymer widely used for medical and pharmaceutical purposes. Different poloxamer grades have been under study for ocular, nasal, topical, rectal, vaginal and uterine use, and are also used in oral preparations. Because of poloxamer's low toxicity and weak immunogenic properties it has been considered suitable also for parenteral drug delivery [22-26]. The reverse phase thermal gelation of the $25 \%(\mathrm{w} / \mathrm{w})$ poloxamer gel makes it an easily injectable liquid when cold $\left(5-10^{\circ} \mathrm{C}\right)$ and it forms a highly viscous gel in situ at a physiological body temperature.

We have previously shown controlled release of ibuprofen through porcine dura mater in vitro from an ibuprofenpoloxamer 407 gel [27]. In vivo lumbar epidural injection of ibuprofen containing poloxamer 407 gel to pigs resulted in analgesia to pinching and reduced systemic absorption of ibuprofen [28]. Epidurally administered ibuprofen does not cause motor blockade $[19,28]$, and in this respect ibuprofen can also be regarded as a promising drug for post-operative spinal pain treatment.

The fate of epidurally administered ibuprofen is not clear, and details of the spinal area kinetics after controlled release epidural poloxamer gel injection are needed. Our hypothesis is that ibuprofen concentration at the epidural injection site can probably be maintained by poloxamer gel and ibuprofen could be "transferred" into intrathecal space in adequate amounts and for a prolonged length of time to produce analgesia at the spinal cord level. The knowledge of ibuprofen epidural pharmacokinetics would be critical for optimizing ibuprofen spinal dose.

The present in vivo study in pigs was designed to characterize and compare the distribution of ibuprofen in the spinal area after an epidural bolus injection of ibuprofen in poloxamer gel or in saline. Ibuprofen concentrations in epidural and intrathecal space as well as in plasma were investigated using microdialysis techniques which allowed continuous sampling from the spinal spaces.

\section{Materials and methods}

\subsection{Drug formulation}

The poloxamer gel was prepared as previously using the cold preparation technique [29]. An appropriate amount (25\% w/w) of poloxamer $407\left(\left(\mathrm{HO}\left(\mathrm{C}_{2} \mathrm{H}_{4} \mathrm{O}\right)_{101}\left(\mathrm{C}_{3} \mathrm{H}_{6} \mathrm{O}\right)_{56}\left(\mathrm{C}_{2} \mathrm{H}_{4} \mathrm{O}\right)_{101} \mathrm{H}\right.\right.$, i.e., polyoxyethylene - polyoxypropylene block co-polymer) (Lutrol F-127, BASF, USA) was added into a cold solution $\left(5 \pm 1{ }^{\circ} \mathrm{C}\right)$ while maintaining constant agitation with a magnetic stirrer. The gel was stored at $4{ }^{\circ} \mathrm{C}$ until a clear solution was formed. Ibuprofen-Na $\left(\mathrm{C}_{13} \mathrm{H}_{17} \mathrm{NaO}_{2}\right.$, i.e., sodium 2-[4-(2-methylpropyl) phenyl] propionate) (Knoll Pharm., United Kingdom) (2\% corresponding to $1.6 \%$ ibuprofen) was added in the gel and the $\mathrm{pH}$ was adjusted carefully to 7.4 with $\mathrm{HCl}$ solution. The $\mathrm{pH}$ was measured with a $\mathrm{pH}$ meter (Mettler, Halstend, UK) while the gel was in the liquid state at $4{ }^{\circ} \mathrm{C}$. Ibuprofen-Na-solution (2\%) was used as the control formulation.

The viscosity measurement was a quality control method to assess the behavior of the gel at body temperature. The apparent viscosity value of the $2 \%$ ibuprofen $\mathrm{Na}$ containing $25 \%$ poloxamer gel was after $10 \mathrm{~min}$ rotation at $37^{\circ} \mathrm{C} 67.1 \pm 1.8 \mathrm{~Pa} \cdot \mathrm{s}$ (Brookfield digital rheometer DV-III, spindle RV7, Brookfield RVT laboratories, Stoughton, USA). The temperature of the gel samples was adjusted to $37^{\circ} \mathrm{C}$ using a thermostated water jacket.

\subsection{Microdialysis experiment}

\subsubsection{Animals}

The animal study was approved by the University of Washington's Institutional Animal Care and Use Committee
(Seattle, Washington). The guidelines of American Association for Laboratory Animal Care (NIH Publications) for the use of experimental animals were followed throughout the experiments. The animals used were healthy farm-raced pigs $(n=12)$ weighing $11-14 \mathrm{~kg}$. Before the experiment the animals were on ad libitum diet and they were housed in a $12 \mathrm{~h}$ light-dark cycled rooms. The animals were euthanized after the experiment.

The animals were randomly divided into two main study groups: ibuprofen solution $(n=6)$ and ibuprofen poloxamer gel $(n=6)$ groups. The animals were anesthetized by mask inhalation with halothane $(1-2 \%)$ and nitrous oxide $(70 \%)$ in oxygen. The muscle functions were controlled by an intramuscular succinylcholine injection $(100 \mathrm{mg}$ ). The orotracheal tube was placed and anesthesia was maintained with isoflurane (1-2\%) in balance oxygen. Animals were mechanically ventilated to maintain end-tidal $\mathrm{CO}_{2}$ between 36 and $40 \mathrm{mmHg}$. A Datex (Helsinki, Finland) model F-W8-28-01 airway gas analyzer was used to measure end-tidal $\mathrm{CO}_{2}$ and isoflurane concentrations. The body temperature of the anesthetized animal was maintained at $37-38^{\circ} \mathrm{C}$ by a heat-lamp controlled by a rectal thermometer system. The right femoral artery of the animal was cannulated for blood sampling. Blood pressure and heart rate were measured by pressure transducer. The transducers used were Hospira Transpac IV Monitoring Kit (Hospira Inc., Lake Forest, Il, USA). Saline solution infusion was given as a maintenance fluid through the cannulated right femoral vein and was administered at the rate of $4 \mathrm{ml} / \mathrm{kg} / \mathrm{h}$ using volume controlled pump (Abbot/Shaw Lifecare Pump Model 4, Abbot Laboratories, Alameda, CA, USA).

\subsubsection{Implantation of microdialysis probes and drug administration}

The microdialysis technique used was a slightly modified version of the method previously used in this laboratory for local anesthetic analysis [30,31]. Using microsurgical technique, the vertebral laminas were exposed posteriorly between T11 and L5. The epidural probe was inserted through the ligamentum flavum between L1 and L2 and was directed cephalad in the posterior epidural space. The intrathecal probe was directed caudal in the subarachnoid space. The probes were secured to be in place by cyanoacrylate glue. The microdialysis probes were made from cellulose dialysis fibers (Spectrum Medical Industries, Inc., Houston, Texas) with a $215 \mu \mathrm{m}$ inside diameter, a $235 \mu \mathrm{m}$ outside diameter, and a molecular weight cutoff of 6000 Daltons. The probes were perfused with bicarbonate buffered mock cerebral spinal fluid $\left(\mathrm{NaCl} 140 \mathrm{mEq}, \mathrm{NaHCO}_{3} 25 \mathrm{mEq}, \mathrm{KCl}\right.$ $2.9 \mathrm{mEq}, \mathrm{MgCl}_{2} 0.4 \mathrm{mEq}$, urea $3.5 \mathrm{mEq}$, glucose $4.0 \mathrm{mEq}, \mathrm{CaCl}_{2}$ $2.0 \mathrm{mEq} ; \mathrm{pH}=7.38-7.42 ; 292-298 \mathrm{mOsm})$ through which $5 \%$ $\mathrm{CO}_{2} / 95 \%$ air gas was bubbled. The microdialysis probes were connected to the cellulose tubing and syringe pump. The syringe pump (Harvard Apparatus Inc., model 22, Holliston, MA) was used to pump mock CSF through the dialysis probes at the rate of $10 \mu \mathrm{l} / \mathrm{min}$.

The $2 \%$ ibuprofen-Na containing poloxamer gel or $2 \%$ ibuprofen Na solution was administered as a single dose epidural injection into the 5th lumbar interspace through a single G20 epidural catheter (B Braun Medical, Bethlehem, PA) connected to a syringe pump (Harvard apparatus, USA) using a speed of $2 \mathrm{ml} / \mathrm{min}$. The formulations were injected cold $\left(4-8^{\circ} \mathrm{C}\right)$ when the gel was in the liquid state.

At the end of the experiments Richardson's blue was injected into the epidural space via the epidural catheter. The spinal cord and epidural catheter were removed. The intrathecal catheter was removed and the spinal cord was longitudinally sectioned to ascertain that the spinal membranes had remained intact, excluding the catheter insertion holes, and the tissue samples were examined under a dissecting microscope. 


\subsection{Pharmacokinetic experimentation}

\subsubsection{Epidural and intrathecal ibuprofen concentration assay}

Dialysis samples from epidural and intrathecal spaces were collected at $0,5,10,15,20,25,30,40,50,60 \mathrm{~min}$ and then every 20 min until 240 min after the ibuprofen gel or ibuprofen solution injection. The samples were stored at $-20^{\circ} \mathrm{C}$ until analysis.

Ibuprofen concentrations of the epidural and intrathecal dialysate and plasma samples were determined by HPLC at a wavelength of $222 \mathrm{~nm}$ using a modified version of a method described by Minkler and Hoppel [32]. A supelcosil LC-18DB column (Supelco, $5 \mu \mathrm{m}, 125 \AA ̊, 1.6 \times 1500 \mathrm{~mm}$ ) (Waters Ltd., USA-Milford) was used at ambient temperature. The isocratic mobile phase was acetonitrile: deionized water $(40: 60 \mathrm{v} / \mathrm{v})$, and the $\mathrm{pH}$ was adjusted to 6.2 with phosphoric acid. The flow rate was $2 \mathrm{ml} / \mathrm{min}$. The accuracy and reproducibility of the method were assessed according to recommendations [33]. The coefficient of variation of intra-assay variability was $3 \%$ or less. The detection limit was $0.05 \mu \mathrm{g} / \mathrm{ml}$.

\subsubsection{Plasma ibuprofen concentration assay}

Blood samples were collected into EDTA tubes from the cannulated right brachial vein $0,5,10,20,30,60,90,120,150,180$ and 240 min after the injection. Plasma was separated by centrifugation at $3000 \mathrm{rpm}$ for $10 \mathrm{~min}$ and stored in plastic tubes at $-20^{\circ} \mathrm{C}$ until analysis.

Ibuprofen plasma concentrations were determined using high performance liquid chromatography (HPLC) at a wavelength of $222 \mathrm{~nm}$ using a slightly modified version of a method described by Averginos and Hutt [34]. A reversed-phase $C_{18}$ column ( $\mu$ Bondapak $10 \mu \mathrm{m}, 125 \AA, 3.9 \times 300 \mathrm{~mm}$ ) (Waters Ltd., USA-Milford) combined with a guard column ( $\mu$ Bondapak) was used at ambient temperature. The isocratic mobile phase was acetonitrile: $0.1 \mathrm{M}$ sodium acetate $(35: 65 \mathrm{v} / \mathrm{v})$, and the $\mathrm{pH}$ was adjusted to 6.2 with glacial acetic acid. The flow rate was $2 \mathrm{ml} / \mathrm{min}$. The accuracy of the method was tested according to recommendations [33]. The reproducibility of the method was investigated by the repeated analysis $(n=6)$ of plasma samples spiked with ibuprofen at concentrations of 0.1 and $20 \mu \mathrm{g} / \mathrm{ml}$. The coefficient of variation of intra-assay variability was $2 \%$ or less. The detection limit was $0.05 \mu \mathrm{g} / \mathrm{ml}$.

\subsubsection{Pharmacokinetic parameters and statistics}

The pharmacokinetic parameters assessed from the epidural and intrathecal microdialysis samples and the plasma samples were the maximum epidural dialysate, intrathecal dialysate and plasma concentration $\left(C_{\max }\right)$, as well as the time of peak epidural dialysate, intrathecal dialysate and plasma concentration $\left(t_{\max }\right)$, the area under the concentration-time curve from time zero to infinity $\left(\mathrm{AUC}_{0-\infty}\right)$, the area under the concentration-time curve

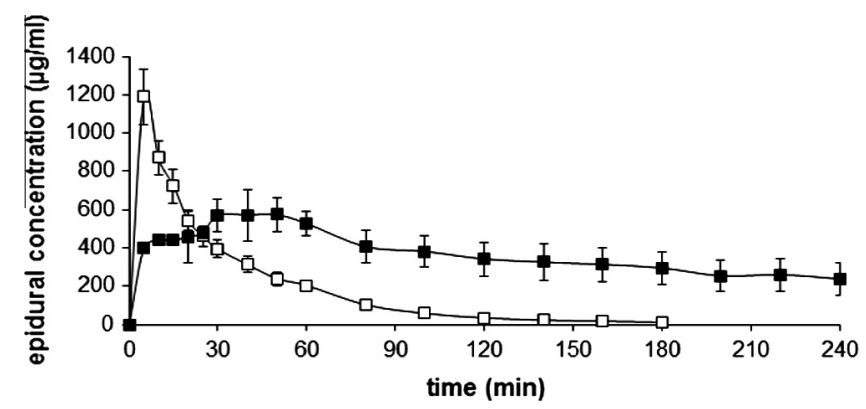

Fig. 1. Mean epidural dialysis concentrations of ibuprofen in pigs after epidural injection of $40 \mathrm{mg}$ ibuprofen in poloxamer gel or solution. Means \pm SEM are presented. Symbols: $\square$ gel $(n=6)$, $\square$ solution $(n=6)$. from time zero to the last measured point $\left(\mathrm{AUC}_{0-\mathrm{t}}\right)$, the apparent elimination half-life $\left(t_{1 / 2}\right)$, and the mean residence time (MRT). The analyses were performed with PK Solution 2.0 software (Summit Research Services, Montrose, Colorado, USA). The measured $\mathrm{C}_{\max }$ and $\mathrm{t}_{\max }$ values were used as such. The AUC and MRT values were calculated according to the trapezoidal method without logarithmic transformation.

The results are expressed as means \pm SEM. Statistical analysis was performed. Intergroup comparisons for all data were performed using analysis of variance (ANOVA). $t_{\max }$ values have been analyzed by Mann-Whitney $U$ test. For all analyses, differences were considered statistically significant at a value of $\mathrm{p}<0.05$.

\section{Results}

\subsection{Epidural space pharmacokinetics}

The ibuprofen concentrations after the poloxamer gel injection were much lower but lasted much longer as compared with the solution injection (Fig. 1). The epidural AUC values were significantly higher after epidural gel injection of ibuprofen compared with the corresponding solution injection (Table 1). The maximum epidural concentration of ibuprofen $(1189 \mu \mathrm{g} / \mathrm{ml})$ was reached 5 min after the epidural injection of ibuprofen solution, while the $\mathrm{C}_{\max }(614 \mu \mathrm{g} / \mathrm{ml})$ after the gel injection was reached in $34 \mathrm{~min}$. The MRT and $t_{1 / 2}$ values were significantly $(\mathrm{p}<0.001)$ longer after the gel injection than after the solution injection.

\subsection{Intrathecal space pharmacokinetics}

The difference in the intrathecal concentrations of ibuprofen after the epidural gel injection compared with epidural solution

Table 1

Epidural pharmacokinetic parameters after epidural injection of $40 \mathrm{mg}$ dose of ibuprofen poloxamer gel $(n=6)$ or ibuprofen solution $(n=6)$. Means \pm SEM are presented.

\begin{tabular}{lll}
\hline Parameter & Gel & Solution \\
\hline $\mathrm{AUC}_{0-\infty}\left(\mu \mathrm{g} / \mathrm{ml} \cdot \mathrm{min}^{-1}\right)$ & $12572 \pm 7860^{* * *}$ & $3588 \pm 711$ \\
$\mathrm{AUC}_{0-\mathrm{t}}\left(\mu \mathrm{g} / \mathrm{ml} \cdot \mathrm{min}^{-1}\right)$ & $9832 \pm 5612^{* *}$ & $3530 \pm 707$ \\
$\mathrm{C}_{\max }(\mu \mathrm{g} / \mathrm{ml})^{\mathrm{a}}$ & $614 \pm 271^{* *}$ & $1189 \pm 286$ \\
$\mathrm{t}_{\max }(\mathrm{min})^{\mathrm{a}}$ & $34.1 \pm 18.5^{* *}$ & $5.1 \pm 0.1$ \\
$\mathrm{MRT}(\min )$ & $209 \pm 43^{* * *}$ & $38.2 \pm 7.4$ \\
$\mathrm{t}_{1 / 2}(\min )$ & $132 \pm 78^{* * *}$ & $31.2 \pm 6.1$
\end{tabular}

Significant difference ${ }^{*} \mathrm{p}<0.05,{ }^{* *} \mathrm{p}<0.01,{ }^{* * *} \mathrm{p}<0.001$ compared with epidural solution.

a The $C_{\max }$ and $t_{\max }$ are apparent values.

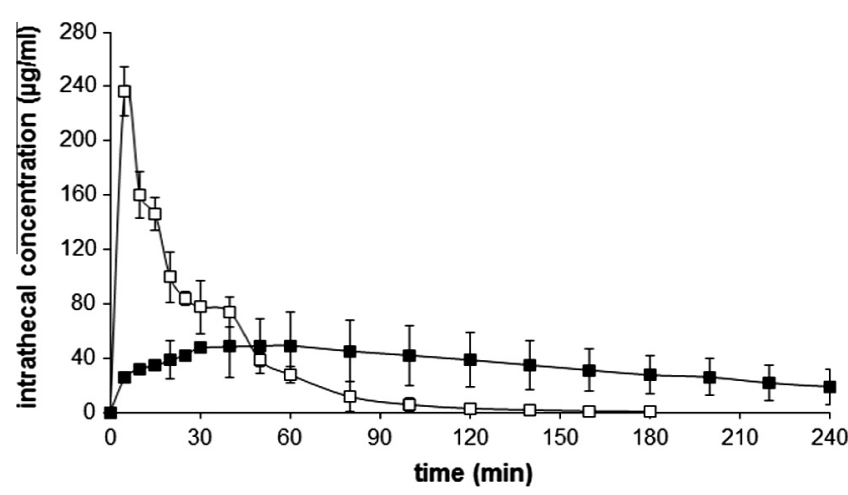

Fig. 2. Mean intrathecal dialysis concentrations of ibuprofen in pigs after epidural injection of $40 \mathrm{mg}$ ibuprofen in poloxamer gel or solution. Means \pm SEM are presented. Symbols: $\mathbf{a g e l}(n=6), \square$ solution $(n=6)$. 
injection is depicted in Fig. 2. After epidural gel injection intrathecal $C_{\max }(45 \mu \mathrm{g} / \mathrm{ml})$ was reached in 55 min while after solution injection $C_{\max }(238 \mu \mathrm{g} / \mathrm{ml})$ occurred after $11 \mathrm{~min}$ (Table 2). The MRT of ibuprofen increased significantly $(\mathrm{p}<0.001)$ after epidural injection of the gel $(131 \mathrm{~min})$ as compared with the solution (43 min). The elimination $t_{1 / 2}$ time for ibuprofen was also significantly $(\mathrm{p}<0.001)$ longer after the gel injection compared with the solution.

\subsection{Systemic absorption}

The epidural injection of ibuprofen gel prolonged the absorption of ibuprofen into blood compared with the epidural solution injection of ibuprofen (Fig. 3). The maximum plasma ibuprofen concentration $\left(\mathrm{C}_{\max } 2.3 \mu \mathrm{g} / \mathrm{ml}\right)$ after the epidural gel injection was reached at about $1 \mathrm{~h}$, while after solution injection $C_{\max }$ $(9.8 \mu \mathrm{g} / \mathrm{ml})$ was reached already $35 \mathrm{~min}$ earlier (Table 3$)$. The MRT and $t_{1 / 2}$ values were significantly larger after the gel injection compared with the solution. Furthermore, the AUC values were significantly smaller $(\mathrm{p}<0.001)$ after epidural gel injection

Table 2

Intrathecal pharmacokinetic parameters after epidural injection of $40 \mathrm{mg}$ dose of ibuprofen poloxamer gel $(n=6)$ or ibuprofen solution $(n=6)$. Means \pm SEM are presented.

\begin{tabular}{lll}
\hline Parameter & Gel & Solution \\
\hline $\mathrm{AUC}_{0-\infty}\left(\mu \mathrm{g} / \mathrm{ml} \cdot \mathrm{min}^{-1}\right)$ & $3850 \pm 2766^{* * *}$ & $647 \pm 514$ \\
$\mathrm{AUC}_{0-\mathrm{t}}\left(\mu \mathrm{g} / \mathrm{ml} \cdot \mathrm{min}^{-1}\right)$ & $3516 \pm 2644^{* * *}$ & $645 \pm 512$ \\
$\mathrm{C}_{\max }(\mu \mathrm{g} / \mathrm{ml})^{\mathrm{a}}$ & $45.9 \pm 17.7^{* *}$ & $238 \pm 208$ \\
$\mathrm{t}_{\max }(\mathrm{min})^{\mathrm{a}}$ & $55.0 \pm 5^{* *}$ & $11.1 \pm 5.8$ \\
$\mathrm{MRT}_{(\mathrm{min})}$ & $131 \pm 33^{* * *}$ & $43.8 \pm 24.7$ \\
$\mathrm{t}_{1 / 2}(\mathrm{~min})$ & $86.8 \pm 51^{* *}$ & $31.1 \pm 7.4$
\end{tabular}

Significant difference ${ }^{*} \mathrm{p}<0.05,{ }^{* *} \mathrm{p}<0.01,{ }^{* * *} \mathrm{p}<0.001$ compared with epidural solution.

a The $\mathrm{C}_{\max }$ and $\mathrm{t}_{\max }$ are apparent values.

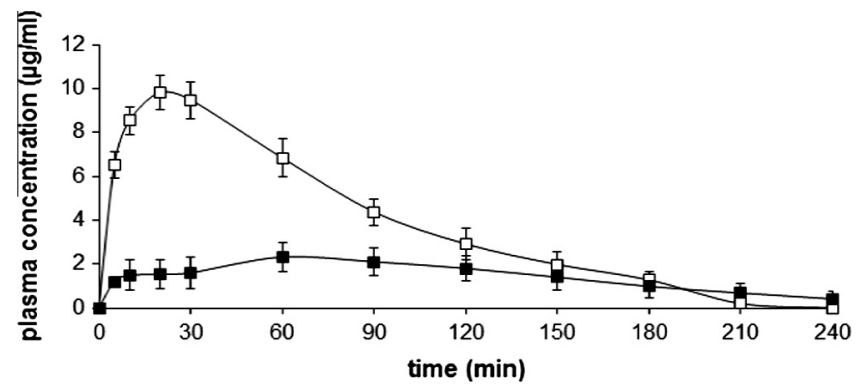

Fig. 3. Mean plasma concentrations of ibuprofen in pigs after epidural injection of $40 \mathrm{mg}$ ibuprofen in poloxamer gel or solution. Means \pm SEM are presented. Symbols: $\mathbf{q}$ gel $(\mathrm{n}=6), \square$ solution $(\mathrm{n}=6)$.

Table 3

Plasma pharmacokinetic parameters after epidural injection of $40 \mathrm{mg}$ dose of ibuprofen poloxamer gel $(n=6)$ or ibuprofen solution $(n=6)$. Means \pm SEM are presented.

\begin{tabular}{lll}
\hline Parameter & Gel & Solution \\
\hline $\mathrm{AUC}_{0-\infty}\left(\mu \mathrm{g} / \mathrm{ml} \cdot \mathrm{min}^{-1}\right)$ & $622 \pm 426^{* * *}$ & $1121 \pm 382$ \\
$\mathrm{AUC}_{0-\mathrm{t}}\left(\mu \mathrm{g} / \mathrm{ml} \cdot \mathrm{min}^{-1}\right)$ & $604 \pm 284^{* *}$ & $942 \pm 368$ \\
$\mathrm{C}_{\max }(\mu \mathrm{g} / \mathrm{ml})^{\mathrm{a}}$ & $2.34 \pm 1.15^{* *}$ & $9.8 \pm 2.3$ \\
$\mathrm{t}_{\max }(\mathrm{min})^{\mathrm{a}}$ & $58.2 \pm 14.7^{* *}$ & $24.2 \pm 4.8$ \\
$\left.\mathrm{MRT}^{\mathrm{m}} \mathrm{min}\right)$ & $45.9 \pm 10.4^{* * *}$ & $31.0 \pm 31$ \\
$\mathrm{t}_{1 / 2}(\min )$ & $23.0 \pm 9.1^{* * *}$ & $19.1 \pm 34.9$ \\
\hline
\end{tabular}

Significant difference ${ }^{*} \mathrm{p}<0.05,{ }^{* *} \mathrm{p}<0.01,{ }^{* * *} \mathrm{p}<0.001$ compared with epidural solution.

a The $C_{\max }$ and $t_{\max }$ are apparent values. $\left(604 \mu \mathrm{g} / \mathrm{ml} \cdot \mathrm{min}^{-1}\right)$ compared with the epidural solution injection $\left(942 \mu \mathrm{g} / \mathrm{ml} \cdot \mathrm{min}^{-1}\right)$.

\section{Discussion}

\subsection{Epidural and intrathecal concentrations}

An important finding was that the intrathecal AUC of ibuprofen was significantly larger after epidural poloxamer gel injection compared with the epidural solution injection (Tables 1 and 2). The ibuprofen concentrations in the epidural and intrathecal spaces remained at a steady-state level in the poloxamer gel group for a long time (Figs. 1 and 2). The cold $25 \%$ poloxamer gel injected into the epidural space rapidly forms a soft but compact $2-3 \mathrm{~cm}$ wide structure of poloxamer gel at and around the epidural injection site [28]. Ibuprofen is an amphiphilic molecule containing both hydrophilic and hydrophobic regions [35,36], and it forms micelles in solutions [37]. The micelle forming capacity of ibuprofen in solutions probably decreases the surface tension at the dural membrane interface thus speeding up ibuprofen molecule diffusion. Interestingly the epidural $\mathrm{C}_{\max }$ of ibuprofen after ibuprofen solution administration was lower than expected based on the dose administered. Due to ibuprofen's lipophilic nature, part of the dose may have rapidly distributed into epidural tissues, and into epidural fat in particular. The lipophilicity of the epidurally administered drug may have a significant impact on the spinal kinetics through uptake in epidural tissues, in particular epidural fat [38]. The more lipophilic the local anesthetics the more drug has been shown to be absorbed in epidural fat [39-41]. Theoretical lipophilicity of ibuprofen ( $\log$ P 4.0) is near to that of the commonly used epidural anesthetic bupivacaine ( $\log P$ 3.4) and analgesic sufentanil $(\log P$ 3.5). The $\mathrm{pK}_{\mathrm{a}}$ of ibuprofen is low, i.e., 3.5 [42], which suggests strong ionization at physiological $\mathrm{pH}$. Therefore, ibuprofen in the epidural space fairly poorly penetrates membranes, unlike more lipophilic drugs, e.g. local anesthetics and morphine [38]. On the other hand, because of a carboxyl group in the molecular structure, ibuprofen is able to form hydrogen bonds with various epidural tissue structural components, which also can lead to a reduced amount of ibuprofen in the epidural space. The epidural AUC of ibuprofen was, however, over threefold larger after epidural ibuprofen gel injection compared with the ibuprofen solution injection $(\mathrm{p}<0.001)$ suggesting that the bioavailability of ibuprofen in the CSF was improved by $25 \%$ poloxamer gel.

Based on the rate parameter results (MRT, $t_{\max }$ and $C_{\max }$ ) of epidural and intrathecal samples ibuprofen diffused steadily from the gel in the epidural space through the spinal membranes into the intrathecal space and CSF. It remains to be shown whether such intrathecal concentrations are able to relieve pain associated with e.g. surgery. In the rat paw formalin test Malmberg and Yaksh [43] found that a spinal analgesic effect could be achieved with about only a one hundredth part of an effective systemic dose of variety of analgesics, including ibuprofen.

\subsection{Systemic absorption after epidural injection}

Rapid systemic absorption or extensive spread in the CSF of drug molecules after epidural administration, is the most common reason of unwanted adverse-effects of epidurally used drugs. The physicochemical properties of diffusing molecules are important in determining the permeation of molecules through spinal meninges and subsequent distribution into blood, CSF and spinal tissues [41]. As seen in the present study, injection of ibuprofen solution resulted in initially very high epidural and intrathecal concentrations (Figs. 1 and 2). This was followed by a relatively rapid concentration decline, and a concomitant rise in ibuprofen 
plasma concentrations (Fig. 3). Poloxamer gel reduced and slowed the systemic absorption of ibuprofen. Although plasma levels of ibuprofen after epidural gel administration were very low, and clearly lower than that $(7 \mu \mathrm{g} / \mathrm{ml})$ was found to reduce pain in man [44], constant systemic absorption into blood circulation from spinal area was observed for 3-4 h. The vascular network in the epidural space and of the meninges are potential sites for any drug to be cleared into the systemic circulation before they reach the spinal cord [45].

\subsection{Poloxamer gel effects on epidural ibuprofen kinetics}

Drug movement through the spinal meninges is diffusion, and in in vitro studies evidence of active transport or facilitated diffusion of drug molecules has not been seen [46]. After injection of the ibuprofen solution, fast diffusion through the epidural membrane seems to correlate with fast redistribution into the plasma and decreased efficacy at the spinal site. Based on the present study, it can be concluded, that poloxamer gel can improve utilization and therapeutic index of epidurally administered ibuprofen. The gel can permit more accurate targeting of drug molecules to the specific spinal cord segments responsible for pain because it prevents wide spread of drug molecules within the epidural space, which occurs with injected solutions. The amount of ibuprofen entering the intrathecal space was sixfold higher after ibuprofen gel compared with solution injection (Tables 1 and 2), and the escape from epidural space to plasma was significantly reduced (Table 3). This is in line with and complements our previous in vitro dura mater permeability findings in which ibuprofen permeability through porcine dura mater membrane after solution injection was fivefold higher compared to that after poloxamer gel; apparent permeability coefficients being $35.5 \times 10^{-6} \mathrm{~cm} / \mathrm{s}$ and $7.3 \times 10^{-6} \mathrm{~cm} / \mathrm{s}$, respectively [27]. In vitro permeability of ibuprofen through dura mater in case of solution was in the beginning linear as a function of time and continued to be linear as a function of square root of time from $60 \mathrm{~min}$ forward. In contrast, the cumulative amount of ibuprofen permeated in vitro through dura mater membrane from the gel as a function of time was linear [27]. However, in vivo the tight junctions of arachnoid mater seem to form a strong functional barrier to diffusion in the meninges which thus can decrease the in vitro observed permeation $[46,47]$.

The innermost structure of poloxamer gel is composed of cubically orientated micellar subunits where the inner part is hydrophobic polypropylene oxide and outer polyethylene oxide part hydrophilic $[29,48]$. Polyethylene oxide-polypropylene oxide polymers have been found to increase drug concentration levels in brain tissues by producing drug accumulation in selected organs and even overcome blood-brain-barriers intrinsic drug resistance $[49,50]$. The intrathecal dialysis concentrations show that $25 \%$ poloxamer gel, in addition to being a diffusion targeting mechanical gel matrix, could act as an ibuprofen absorption increasing system on the epidural membrane interface.

Although the fate of drugs given epidurally is complicated, the amount of drug transferred through the dural membrane from the epidural space and entering the intrathecal space determines the anesthetic effect $[45,51]$. Epidural and intrathecal elimination of ibuprofen after epidural gel administration (Figs. 1 and 2) was linear as a function of time, while the elimination after the solution was more of first order. The poloxamer gel was able to reduce peak concentrations of ibuprofen and increase its total exposure over time. Based on our results 25\% poloxamer gel could ensure a constant ibuprofen concentration in the spinal nervous tissue and a prolonged duration of analgesic action, i.e. pain-suppressing activity. While the redistribution of ibuprofen from epidural space to blood circulation is minimized by the gel, ibuprofen entry into the central neuroaxis will be enhanced.

\subsection{Safety of poloxamer}

Poloxamer is compatible with many drugs and forms in situ a controlled release system increasing residence time of the drug at the injection site. Many gels have limitations in terms of strength, e.g. pore size of collagen gels is often too large to control diffusion [52,53]. The properties of poloxamer gel still seem very promising for injectable controlled release use, and therefore meaningful to be studied further. The aqueous systems of poloxamers 407 are smart, temperature stimuli-responsive chemically and physically reducible and stable systems [26,54,55]. Poloxamer 407 is generally classified as an inactive molecule and based on the available data it can be considered as non-toxic and biocompatible [56]. In rabbits, only very high intraperitoneal doses (140 mg/kg) of some poloxamer types have resulted in lipid metabolism alterations [57].

\subsection{Microdialysis and epidural space kinetics}

Epidural and intrathecal pharmacokinetics of drugs is a complex area of kinetics. Microdialysis techniques are sensitive methods with which also distribution of drugs in the spinal area can be studied [30,58-61]. Structurally the epidural space is the outermost part of the spinal canal, which is formed by the surrounding vertebrae outside the dura mater of the spinal meninges. Dura mater and arachnoid mater are attached to each other and enclose the subarachnoid space, i.e., the intrathecal space, the cerebrospinal fluid, and the spinal cord (Fig. 4). The drug molecules penetrate the dural and arachnoid membranes, in order to get access to the nerve roots and the spinal cord in the subarachnoid space. Four main mechanisms in drug delivery from epidural space are competing, i.e., diffusion through the spinal meanings, systemic absorption, distribution into the epidural fat and diffusion through dural nerve root cuffs $[47,62,63]$. Of these the amount of drugs diffusing across the spinal meninges is the most important factor affecting drug delivery into the spinal cord nerve tissue and thus determining the analgesic effect after epidural administration. Microdialysis makes it possible to measure ibuprofen concentrations in the fluid-free epidural space and the intrathecal space without altering the dynamics of CSF.

\subsection{The limitations of describing epidural drug behavior and spinal drug delivery with microdialysis}

It is not ethical or possible to study spinal distribution of drugs in vivo in humans during formulation development. Microdialysis allows continuous sampling of spinal region after epidural ibuprofen administration and the true pharmacokinetics of the epidural space can be evaluated. There are some minor differences in spinal

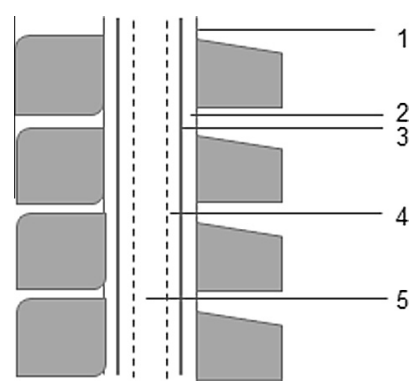

Fig. 4. Schematic cross-sectional illustration of the spinal canal inside the vertebral canal of the spine. 1. Ligamentum flavum, 2. Epidural space, 3. Dura mater with attached arachnoid mater, 4. Intrathecal space, i.e., subarachnoid space with cerebrospinal fluid (CSF), 5. The spinal cord and CSF. 
anatomy between pigs and humans, e.g., in caudal extension of the spinal cord. However, the background literature data of pigs and their use in central nervous system studies indicate that regarding anatomy, physiology and pharmacology pigs very closely resemble those of humans $[64,65]$. The possible ibuprofen absorption in the epidural fat remained as an uncontrollable variable in this study design, but because of minuscule epidural fat amount in the young animals ibuprofen absorption into plasma could be considered as the most prominent epidural bioavailability reducing factor. The microdialysis method has been used successfully previously for other commonly epidurally used drugs such as bupivacaine and opioids [30,31]. It is a reproducible and applicable method.

\section{Conclusions}

The present microdialysis study indicated that the relative bioavailability of ibuprofen in the CSF was increased after epidural injection of the $25 \%$ poloxamer 407 gel. The poloxamer gel permitted accurate and effective targeting of ibuprofen to specific spinal cord segments. It prevented a wide spread of the drug within the epidural space and allowed controlled drug delivery from the epidural space into the intrathecal space. It also seemed to diminish the redistribution of ibuprofen to extraspinal sites, including plasma. In addition to being a diffusion targeting mechanical gel matrix, poloxamer gel seemed act as an ibuprofen epidural permeation enhancing system.

\section{Acknowledgments}

The grants from the Academy of Finland and Alfred Kordelin Foundation (Finland) for the study of A.P. at the University of Washington (Seattle, USA) are greatly acknowledged. The authors wish to thank Prof. Janne Backman (University of Helsinki) for the statistical review of the data. The authors declare that there are no conflict of interests in this study.

\section{References}

[1] L. Langerman, E. Colombo, S. Benita, Spinal anesthesia: significant prolongation of the pharmacological effect of tetracaine with lipid solution of the agent, Anesthesiology 74 (1991) 105-107.

[2] C.M. Bernards, Effect of (hydroxypropyl)-beta-cyclodextrin on flux of morphine, fentanyl, sufentanil, and alfentanil through the spinal meninges of monkey, J. Pharm. Sci. 83 (1994) 620-622.

[3] T. Mashimo, I. Uchida, M. Pak, A. Shibata, S. Nishimura, Y. Inagaki, I. Yoshiya Prolongation of canine epidural anesthesia by liposome encapsulation of lidocaine, Anesth. Analg. 74 (1992) 827-834.

[4] J.M. Malinovsky, J.M. Bernard, P. Le Corre, A. Faivre, J.F. Chatal, M. Pinaud, Extradural bupivacaine-loaded microspheres and spinal cord blood flow in the chronically instrumented rabbit, Clin. Physiol. 17 (4) (1997) 361-370.

[5] M. Ratajczak-Enselme, J.P. Estebe, G. Dollo, F. Chevanne, D. Bec, J.M. Malinovsky, C. Ecoffey, P. Le Corre, Epidural, intrathecal and plasma pharmacokinetics study of epidural ropivacaine in PLGA-microspheres in sheep model, Eur. J. Pharm. Biopharm. 72 (2009) 54-61.

[6] F. Li, D. Liao, J. Liu, L. Xiao, J. Guo, M. Yi, C. Zhou, Emulsified halothane produces long-term epidural anesthetic effect: a study in rabbits, Int. J. Clin. Exp. Pathol. 8 (2015) 4573-4580.

[7] C.F. Weiniger, L. Golovanevski, A.J. Domb, D. Ickowicz, Extended release formulations for local anaesthetic agents, Anaesthesia 67 (2012) 906-916.

[8] S. Sumida, M.R. Lesley, M.N. Hanna, J.D. Murphy, K. Kumar, C.L. Wu, Metaanalysis of the effect of extended-release epidural morphine versus intravenous patient-controlled analgesia on respiratory depression, J. Opioid Manage. 5 (2009) 301-305.

[9] E.R. Viscusi, K.A. Candiotti, E. Onel, M. Morren, G.L. Ludbrook, The pharmacokinetics and pharmacodynamics of liposome bupivacaine administered via a single epidural injection to healthy volunteers, Reg. Anesth. Pain Med. 27 (2012) 616-622.

[10] B. Carvalho, L.M. Roland, L.F. Chu, V.A. Campitelli, E.T. Riley, Single-dose, extended-release epidural morphine (DepoDur) compared to conventional epidural morphine for post-cesarean pain, Anesth. Analg. 105 (2007) 176-183.

[11] A. Uskova, J.E. O'Connor, Liposomal bupivacaine for regional anesthesia, Curr Opin. Anesthesiol. 28 (2015) 593-597.

[12] H.R. Ochs, D.J. Greenbatt, D.R. Abernethy, R.M. Arendt, J. Gerloff, W. Eichelkraut, N. Hahn, Cerebrospinal fluid uptake and peripheral distribution of centrally acting drugs: relation to lipid solubility, J. Pharm. Pharmacol. 37 (1985) 428-431.

[13] E.J. Drower, A. Stapelfeld, R.A. Müller, D.L. Hammond, The antinociceptive effects of prostaglandin antagonist in the rat, Eur. J. Pharmacol. 133 (1987) 249-256.

[14] M. Pellerin, F. Hardy, A. Abergel, D. Boule, J.H. Palacci, P. Babinet, L.N. Wingtin, J. Glowinski, J.F. Amiot, D. Mechali, Chronic refractory pain in cancer patients: value of the spinal injection of lysine acetylsalicylate, Presse Med. 19 (16) (1987) 1465-1468.

[15] J.A. Aldrete, Epidural injections of indomethacin for postlaminectomy syndrome: a preliminary report, Anesth. Analg. 96 (2003) 463-468.

[16] T. Yamamoto, N. Nozaki-Taguchi, Role of spinal cyclooxygenase (COX)-2 on thermal hyperalgesia evoked by carageenan injection in the rat, NeuroReport 8 (1997) 2179-2182.

[17] J.R. Vane, R.M. Botting, Mechanism of action of anti-inflammatory drugs, Int. J. Tissue React. 20 (1998) 3-15.

[18] A.B. Malmberg, T.L. Yaksh, Hyperalgesia mediated by spinal glutamate or substance P receptor blocked by spinal cyclo-oxygenase inhibition, Science 257 (1992) 1276-1278.

[19] K. McCormack, Non-steroidal anti-inflammatory drugs and spinal nociceptive processing, Pain 59 (1994) 9-43.

[20] E.C. Howard, G.R. Murray, T.N. Calvey, N.E. Williams, Prolonged release extradural morphine, Ann. R. Coll. Surg. Engl. 67 (1985) 8-10.

[21] B.C. Wang, D. Li, J.M. Hiller, D.E. Hillman, B.C. Pasternack, H. Turndorf, The antinociceptive effect of $\mathrm{S}-(+)$-ibuprofen in rabbits: epidural versus intravenous administration, Anesth. Analg. 80 (1995) 92-96.

[22] T.P. Johnston, S.C. Miller, Toxicological evaluation of poloxamer vehicles for intramuscular use, J. Parent. Sci. Technol. 39 (1985) 83-88.

[23] E.A. Pec, Z.C. Wout, T.P. Johnston, Biological activity of urease formulated in poloxamer after intraperitoneal injection in rat, J. Pharm. Sci. 81 (1992) 626630.

[24] G. Dumortier, J.L. Grossiord, F. Agnely, J.C. Chaumeil, A review of poloxamer 407 pharmaceutical and pharmacological characteristics, Pharm. Res. 23 (2006) 2709-2728.

[25] D.A. Chiappetta, A. Sosnik, Poly(ethylene oxide)-poly(propylene oxide) block copolymer micelles as drug delivery agents: improved hydrosolubility, stability and bioavailability of drugs, Eur. J. Pharm. Biopharm. 66 (2007) 303-317.

[26] H. Almeida, M.H. Amaral, P. Lobăo, Temperature and pH-stimuli-responsive polymers and their applications in controlled and self-regulated drug delivery, J. Appl. Pharm. Sci. 02 (6) (2012) 1-10.

[27] A. Paavola, J. Yliruusi, P. Rosenberg, Controlled release and dura mater permeability of lidocaine and ibuprofen from injectable poloxamer-based gels, J. Control. Release 52 (1998) 169-178.

[28] A. Paavola, P. Tarkkila, M. Xu, T. Wahlström, J. Yliruusi, P. Rosenberg, Controlled release gel of ibuprofen and lidocaine in epidural use - analgesia and systemic absorption in pigs, Pharm. Res. 15 (1998) 482-487.

[29] J.R. Schmolka, Artificial skin. I. Preparation and properties of Pluronic F-127 gels for treatment of burns, J. Biomed. Mater. Res. 6 (1972) 571-582.

[30] C.M. Bernards, D.D. Shen, E.S. Sterling, J.E. Adkins, L. Risler, B. Philis, W. Ummenhofer, Epidural, cerebrospinal fluid, and plasma pharmackokinetics of epidural opioids: differences between opioids, Anesthesiology 99 (2003) 455465.

[31] C.M. Bernards, Cerebrospinal fluid and spinal cord distribution of baclofen and bupivacaine during slow intrathecal infusion in pigs, Anesthesiology 105 (2006) 169-178

[32] P.E. Minkler, C.L. Hoppel, Determination of ibuprofen in human plasma by high-performance liquid chromatography, J. Chromatogr. 428 (1988) 388-394.

[33] V.P. Shah, K.K. Midha, S. Dighe, I.J. McGilveray, J.P. Skelly, A. Yacobi, T. Layloff, C.T. Viswanathan, C.E. Cook, R.D. McDowall, K.A. Pittman, S. Spector, Analytical methods validation: bioavailability, bioequivalence, and pharmacokinetic studies, Pharm. Res. 9 (1992) 588-592.

[34] A. Avgerinos, A. Hutt, High performance liquid chromatographic determination of ibuprofen in human plasma and urine by direct injection, J. Chromatogr. 380 (1986) 468-471.

[35] A. Fini, G. Fazio, G. Feroci, Solubility and solubilisation properties of nonsteroidal anti-inflammatory drugs, Int. J. Pharm. 126 (1995) 95-102.

[36] M. Meloun, S. Bordovska, L. Galla, The thermodynamic dissociation constant of four non-steroidal anti-inflammatory drugs by the least-square nonlinear regression of multiwavelength spectrophotometric $\mathrm{pH}$-titration data, J. Pharm. Biomed. Anal. 45 (2007) 552-564.

[37] A. Ridell, H. Evertsson, S. Nilsson, L.-O. Sundelöf, Amphiphilic association of ibuprofen and two non-ionic cellulose derivatives in aqueous solutions, J. Pharm. Sci. 88 (11) (1999) 1175-1181.

[38] W.C. Ummenhofer, R.H. Arends, D.D. Shen, C.M. Bernards, Comparative spinal distribution and clearance kinetics of intrathecally administered morphine fentanyl, alfentanil, and sufentanil, Anesthesiology 92 (2000) 739-753.

[39] P.H. Rosenberg, J. Kyttä, A. Alila, Absorption of bupivacaine, etidocaine, lignocaine and ropivacaine into n-heptane, rat sciatic nerve, and human extradural and subcutaneous fat, Br. J. Anaesth. 58 (1986) 310-314.

[40] C. Hansch, J.P. Björkroth, A. Leo, Hydropobicity and central nervous system agents. On the principal of minimal hydrophopicity in drug design, J. Pharm. Sci. 76 (1987) 663-687.

[41] C.M. Bernards, H.F. Hill, Physical and chemical properties of drug molecules governing their diffusion through the spinal meninges, Anesthesiology 77 (1992) 750-756. 
[42] F. Barbato, M.I. La Rotonda, F. Quaglia, Interactions of nonsteroidal antiinflammatory drugs with phospholipids: comparison between octanol/buffer partition coefficients and chromatographic indexes on immobilized artificial membrane, J. Pharm. Sci. 86 (2) (1997) 225-229.

[43] A.B. Malmberg, T.L. Yaksh, Antinociceptive actions of spinal nonsteroidal antiinflammatory agents on the formalin test in the rat, J. Pharmacol. Exp. Ther. 263 (1992) 136-146.

[44] A.E. Steen, P.W. Reeh, G. Geisslinger, K.H. Steen, Plasma levels after peroral and topical ibuprofen and effects upon low pH-induced cutaneous and muscle pain, Eur. J. Pain 4 (2000) 195-209.

[45] C.M. Bernards, Epidural and intrathecal drug movement, in: T.L. Yaksh (Ed.), Spinal Drug Delivery, Elsevier Science B.V., Amsterdam, The Netherlands, 1999, pp. 239-252.

[46] C.M. Bernards, H.F. Hill, The spinal nerve root sleeve is not a preferred route for redistribution of drugs from the epidural space to the spinal cord, Anesthesiology 75 (1991) 827-832.

[47] S. Nabeshima, T.S. Reese, D.M.D. Landis, M.W. Brightman, Junctions in the meninges and marginal glia, J. Comp. Neur. 164 (1975) 127-170.

[48] T. Liu, B. Chu, Formation of homogeneous gel-like phases by mixed triblock copolymer micelles in aqueous solution: FCC to BCC phase transition, J. Appl. Cryst. 33 (2000) 727-730.

[49] E.V. Batrakova, S. Li, D.W. Miller, A.V. Kabanov, Pluronic P85 increases permeability of a broad spectrum of drugs in polarized BBMEC and Caco-2 cell monolayers, Pharm. Res. 16 (1999) 1366-1372.

[50] A.V. Kabanov, E.V. Batrakova, D.W. Miller, Pluronic ${ }^{\circledR}$ block copolymers as modulators of drug efflux transporter activity in blood-brain barrier, Adv. Drug Deliv. Rev. 21 (2003) 151-164.

[51] P.R. Bromage, Epidural Analgesia, W.B. Saunders Co., Philadelphia, 1978.

[52] D.G. Wallace, J. Rosenblatt, Collagen gel systems for sustained delivery and tissue engineering, Adv. Drug Deliv. Rev. 5 (2003) 1631-1649.

[53] M. Foox, M. Zilberman, Drug delivery from gelatin-based systems, Expert Opin. Drug Deliv. 12 (2015) 1547-1563.
[54] E.J. Ricci, L.O. Lunardi, D.M.A. Nanclares, J.M. Marchetti, Sustained release of lidocaine from poloxamer 407 gels, Int. J. Pharm. 288 (2005) 235-244.

[55] L. Klouda, Thermo responsive hydrogels in biomedical applications, a sevenyear update, Eur. J. Pharm. Biopharm. 97 (2015) 338-349.

56] C.G. Cable, Poloxamer, in: R.C. Rowe, PJ. Sheskey, W.G. Cook, M.E. Fenton (Eds.), Handbook of Pharmaceutical Excipients, seventh ed., RPS Publishing Pharmaceutical Press, London, UK, 2012, pp. 573-577.

[57] J.M. Blonder, L. Baird, J.C. Fulfs, G.J. Rosenthal, Dose-dependent hyperlipidemia in rabbits following administration of poloxamer 407 gel, Life Sci. 65 (1999) PL261-PL266.

[58] M. Marsala, A.B. Malmberg, T.L. Yaksh, A chronic spinal dialysis catheter for use in the rat: methodology and application, J. Neurosci. Meth. 62 (1995) 4353.

[59] E.C.M. de Lange, M.R. Bouw, J.W. Mandema, M. Danhof, A.G. de Boer, D.D Breimer, Application of intracerebral microdialysis to study regiona distribution kinetics of drugs in rat brain, Brith. J. Pharmacol. 116 (1995) 2538-2544.

[60] M. Müller, Microdialysis in clinical drug delivery studies, Adv. Drug Deliv. Rev 45 (2000) 255-269.

[61] A. de la Pena, P. Liu, H. Derendorf, Microdialysis in peripherical tissues, Adv. Drug Deliv. Rev. 45 (2000) 189-216.

[62] A. Butler, CSF transport mechanics in the arachnoid villus, Surg. Forum. 28 (1977) 475-476.

[63] M.J.G. Simon, B.T. Veering, Factors affecting the pharmacokinetics and neura block characteristics after epidural administration of local anaesthetics, Eur. J Pain Suppl. 4 (2010) 209-218.

[64] N. Lind, A. Moustgaard, J. Jelsing, G. Vajta, P. Cumming, A. Hansen, The use of pigs in neuroscience: modelling brain disorders, Neurosci. Biobehavioural Rev. 31 (2007) 728-751.

[65] M.M. Swindle, A. Makin, A.J. Herron, F.J. Clubb Jr., K.S. Frazier, Swine as mode in biomedical research and toxicology, Vet. Pathol. 49 (2) (2011) 344-356. 